\title{
Descemet membrane endothelial keratoplasty in a patient with iris-fixated intraocular lens and prior radial keratotomy: a case report
}

\author{
Anvesh Annadanam, Timothy Soeken, Manjool Shah and Nambi Nallasamy*
}

\begin{abstract}
Background: Anterior segment surgeries such as cataract surgery, intraocular lens (IOL) repositioning, and radial keratotomy (RK) may hasten endothelial dysfunction, particularly in the context of pre-existing Fuchs dystrophy, necessitating future corneal transplantation.

Case presentation: A 68-year-old woman with a history of RK with associated irregular astigmatism in both eyes and iris-fixated intraocular lens (IF-IOL) in the left eye presented with six months of decreased vision in the left eye. She was found to have Fuchs dystrophy and underwent DMEK surgery. She had an uncomplicated postoperative course, with uncorrected visual acuity improving to 20/20 three months after surgery.

Conclusion: To our knowledge, this is the first reported case of a highly successful DMEK surgery in a patient with prior RK and IF-IOL.
\end{abstract}

Keywords: DMEK, RK, Iris-fixated IOL, Case report

\section{Background}

Descemet membrane endothelial keratoplasty (DMEK) is a well-established method of corneal transplantation for the treatment of endothelial dysfunction in Fuchs dystrophy [1]. Radial keratotomy (RK) is a method of refractive surgery historically used to correct myopia, involving the creation of radial incisions to flatten the central cornea. Popular in the 1980 s, RK is now largely disfavored due to its numerous complications [2, 3], including irregular astigmatism. Fuchs dystrophy in patients with a history of RK has previously been managed with either Descemet stripping automated endothelial keratoplasty (DSAEK) or penetrating keratoplasty

\footnotetext{
* Correspondence: nnallasa@med.umich.edu

W. K. Kellogg Eye Center, University of Michigan, 1000 Wall St, MI 48105 Ann Arbor, USA
}

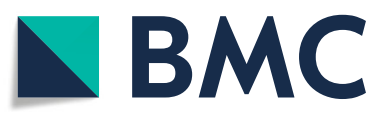

(c) The Author(s). 2021 Open Access This article is licensed under a Creative Commons Attribution 4.0 International License, which permits use, sharing, adaptation, distribution and reproduction in any medium or format, as long as you give appropriate credit to the original author(s) and the source, provide a link to the Creative Commons licence, and indicate if changes were made. The images or other third party material in this article are included in the article's Creative Commons licence, unless indicated otherwise in a credit line to the material. If material is not included in the article's Creative Commons licence and your intended use is not permitted by statutory regulation or exceeds the permitted use, you will need to obtain permission directly from the copyright holder. To view a copy of this licence, visit http://creativecommons.org/licenses/by/4.0/. The Creative Commons Public Domain Dedication waiver (http://creativecommons.org/publicdomain/zero/1.0/) applies to the data made available in this article, unless otherwise stated in a credit line to the data. performed in this population [5, 6].

DMEK can be a challenging procedure to perform on post-vitrectomy eyes and those with potentially unstable intraocular lenses (IOL), such as scleral-fixated IOLs and iris-fixated IOLs (IF-IOLs). Injection of air or sulfur hexafluoride $\left(\mathrm{SF}_{6}\right)$ gas into the anterior chamber after DMEK may potentially dislocate these precarious lenses. However, cases of successful DMEK surgery in patients with scleral-fixated and IF-IOLs have recently been reported [7].

We present a challenging case of a woman who underwent DMEK for corneal endothelial decompensation in the setting of Fuchs dystrophy, with a history of both RK and IF-IOL, as well as prior anterior vitrectomy. To our knowledge, this represents the first report of successful DMEK in a patient with both RK and IF-IOL. 


\section{Case presentation}

A 68-year-old woman was referred to a tertiary eye center for evaluation of Fuchs dystrophy of the left eye. She had reported a 6-month history of decreasing visual acuity (VA), with the left eye worse than the right eye. Her past ocular history includes anterior RK in both eyes 25 years prior to presentation. She had also had cataract extraction in both eyes with in-the-bag IOL placement five years prior to presentation. Following cataract surgery, the patient experienced significant negative dysphotopsias in the left eye and underwent IOL exchange four months after cataract surgery with placement of the new IOL in the ciliary sulcus. Three years later, her sulcus IOL was found to be inferiorly displaced and was repositioned into the capsular bag with placement of a capsular tension segment. A year and a half later, she continued to experience negative dysphotopsias. She underwent repeat IOL exchange with iris-suturing of a Bausch and Lomb 3-piece LI61AO 23.0 diopter lens and anterior vitrectomy, with the intention of addressing negative dysphotopsias by decreasing the depth of the posterior chamber (Fig. 1). Two months following this surgery, her best corrected visual acuity (BCVA) was 20/ 40 in the right eye (OD) and 20/70 in the left eye (OS), but she continued to experience negative dysphotopsias OS. Optical coherence tomography (OCT) of the left macula showed epiretinal membrane (ERM), and she was referred to a local retina specialist for evaluation. At that visit, she was found to have corneal edema of the left eye, diagnosed with Fuchs corneal dystrophy, and referred to our service for assessment. The ERM was deemed to be non-surgical at the time.

On our evaluation, she was found to have a BCVA of 20/30 OD and 20/80 OS, corneal pachymetry of $579 \mu \mathrm{m}$ $\mathrm{OD}$ and $621 \mu \mathrm{m}$ OS, no visible edema OD and $1+$ stromal edema OS, and $2+$ guttae OD and $3+$ pigmented guttae OS. Six RK incisions were identified in both eyes (OU). Her IF-IOL was well-positioned OS, with haptics fixated at two points with $10-0$ Prolene suture, and slight ovalization of the pupil. Preoperative corneal Scheimpflug imaging demonstrated irregular astigmatism OU (Fig. 2). An inferior peripheral laser iridotomy was performed and the patient underwent an uneventful DMEK surgery OS. The donor DMEK tissue $(8.0 \mathrm{~mm}$ diameter) was obtained pre-loaded from the eye bank. A Dutch Ophthalmic Research Center (DORC) tube injector was used to inject the tissue into the anterior chamber (AC). The tissue was opened and positioned using a tapping method. $\mathrm{SF}_{6} 20 \%$ was injected for a full $\mathrm{AC}$ gas fill for $8 \mathrm{~min}$, followed by reduction of the AC gas fill to $80 \%$. Her postoperative course was uncomplicated, with DMEK graft fully attached 360 degrees and improvement of uncorrected VA to 20/20 OS over the next three months. IOL position was unchanged compared to its preoperative position. Cornea remained clear (Fig. 3).

\section{Discussion and conclusions}

With its advantages of minimal invasiveness and excellent postoperative visual outcomes, DMEK surgery has been performed with increasing frequency compared to PK and DSAEK for corneal decompensation for a variety of etiologies $[1,8]$. PK would have addressed RK scars as well as endothelial dysfunction, but the patient would have to potentially endure the longest postoperative recovery course. DSAEK and ultra-thin DSAEK have previously been shown to induce a postoperative hyperopic shift and worse visual acuity outcomes than DMEK [9-11]. At our institution, DSAEK is often considered in aphakia, eyes with a glaucoma drainage device, or prior filtering surgery,

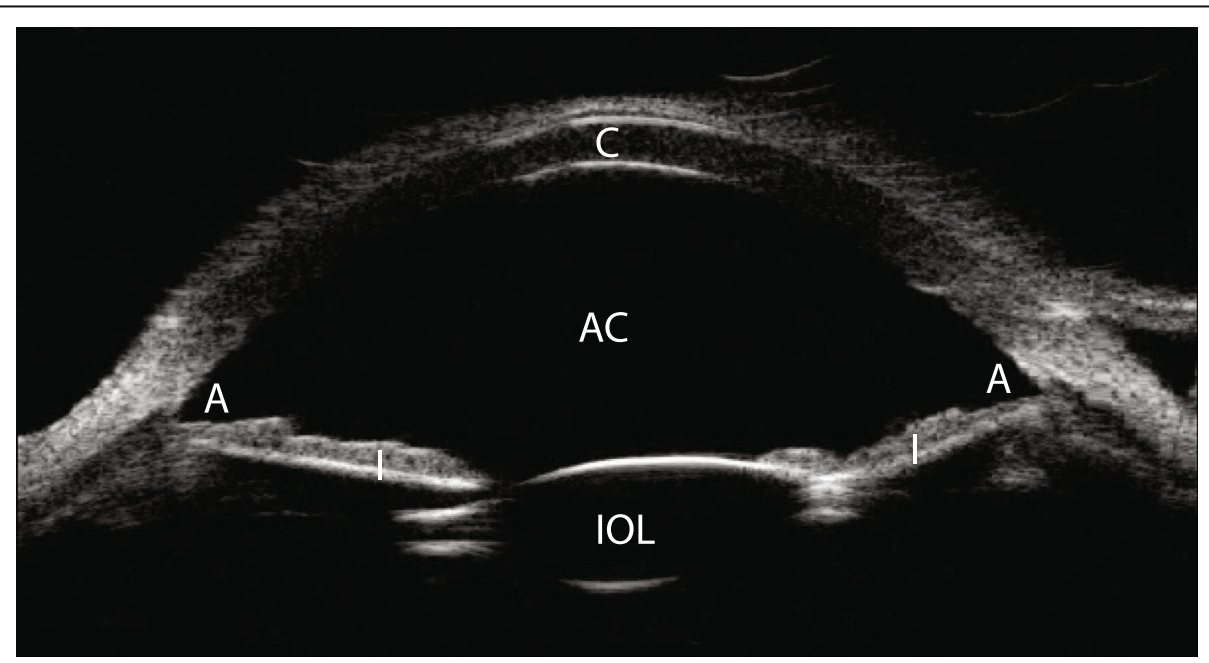

Fig. 1 Horizontal axial view of ultrasound biomicroscopy study showing the relationship of anterior segment structures prior to endothelial keratoplasty. C - cornea, AC - anterior chamber, A - iridocorneal angle, I - iris, IOL - iris-fixated intraocular lens 


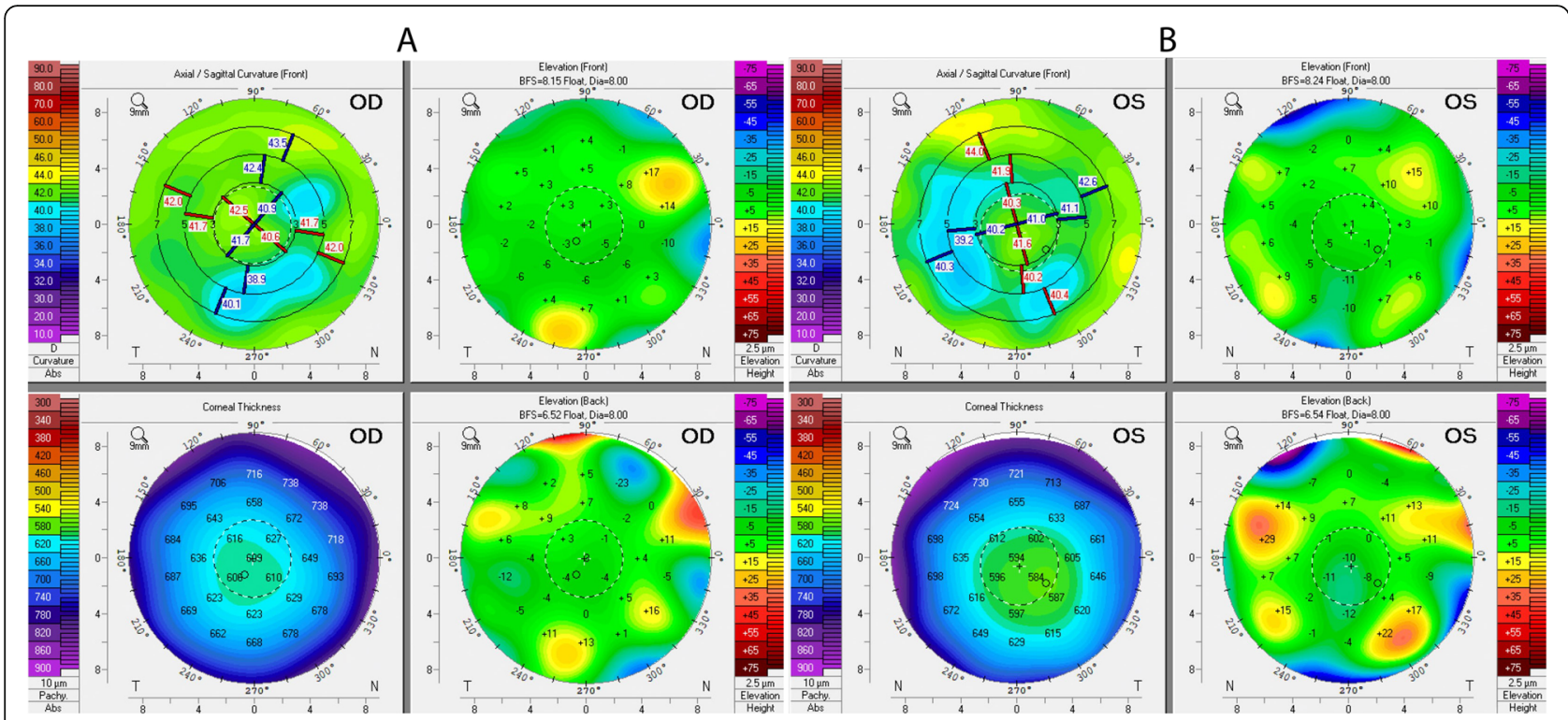

Fig. 2 Pentacam of left cornea. (A) Preoperative scan showing irregular astigmatism, central corneal flattening, and diffuse corneal edema. (B) Postoperative scan showing improved central corneal architecture, decreased astigmatism, and markedly decreased edema

and eyes in which the view of the $\mathrm{AC}$ is considered inadequate for manipulation of a DMEK graft. Since our patient did not meet any of these criteria and was most interested in optimizing postoperative visual outcome, DMEK was selected. However, DMEK may prove difficult if the AC or cornea are altered in any way.

Potential challenges of DMEK in prior RK eyes include posterior corneal scarring (affecting the ability to strip Descemet membrane) and difficulty shallowing the AC, as patients are likely to be axial myopes (as was the patient reported here). Depending on the depth of the RK incision, rupture of an incision may occur during descemetorhexis. The RK incisions themselves weaken the structure of the cornea and can lead to frequent inversion of the corneal curvature during tapping and

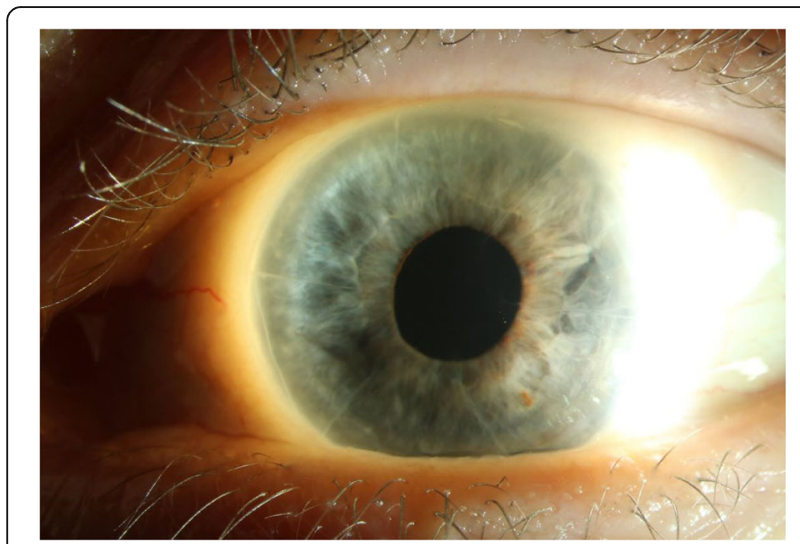

Fig. 3 Postoperative slit lamp photo of the left eye showing a clear cornea anterior chamber shallowing (Fig. 4 A-B). This leaves a moderate to shallow central AC, but a deep paracentral and peripheral $\mathrm{AC}$, making the elimination of peripheral scrolling of the DMEK graft more difficult. Despite these challenges, several cases have been reported of DMEK under RK $[5,6]$. In our patient, we used a pilot bubble (Fig. $4 \mathrm{C}$ ) to facilitate graft manipulation through partial fixation of the central graft during unfurling of the peripheral graft. Sweeping of the pilot bubble through the peripheral AC aided in shallowing the deep peripheral $\mathrm{AC}$ that resulted from intermittent inversion of the corneal curvature. This made it possible to eliminate peripheral curling of the DMEK graft. We also used external pressure on the sclera in conjunction with a pilot bubble to aid in maintaining convexity of the host cornea and graft (Fig. 4 C-D) during unfurling and gas injection. An additional movie file shows key challenges of the case and surgical modifications (see Additional file 1). Though it was not required in this case, posterior segment air infusion could be considered to improve the stability of the $\mathrm{AC}$ in post-vitrectomy eyes such as the one described here.

Further challenges may be present with potentially unstable IOLs such as IF-IOLs [12]. The goal of iris fixation was to decrease negative dysphotopsias by reducing the posterior chamber depth [13]. This method minimizes the distance between the IOL optic and the pupil, making it less likely that the edge of the IOL optic would cast a shadow on the peripheral retina. Prior groups have shown the feasibility of performing DMEK in patients with AC IOLs with good outcomes [14, 15]. Given the stability of the patient's existing IF-IOL, we 

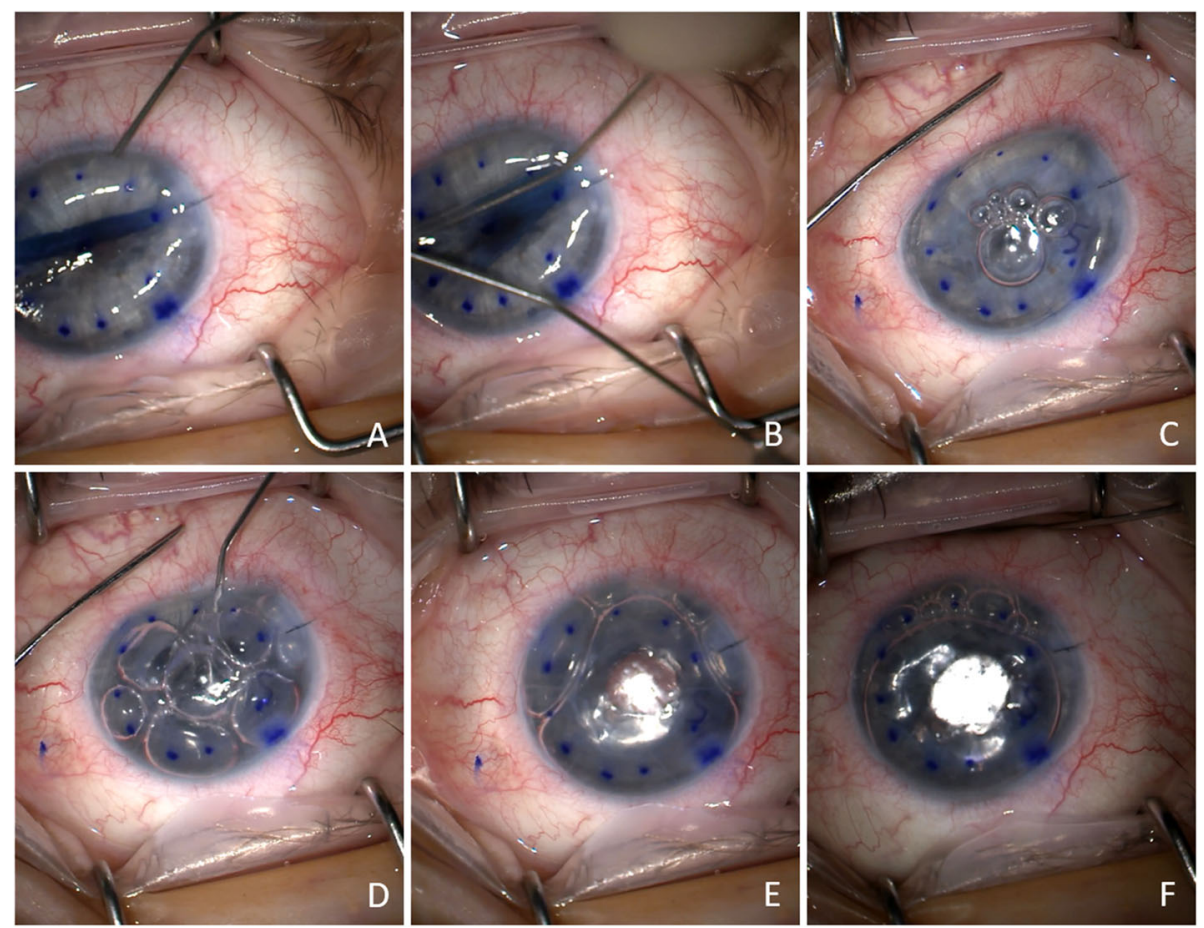

Fig. 4 Intraoperative images demonstrating surgical challenges in DMEK in the context of RK and IF-IOL and techniques to overcome them. (A) Inversion of the corneal curvature during anterior chamber shallowing secondary to RK-associated structural weakening of the cornea. (B) Inversion of the corneal curvature during tapping secondary to RK-associated structural weakening of the cornea. (C) Use of a pilot bubble and external pressure on the sclera from a spatula to enable unfurling of the DMEK graft. (D) Use of external pressure on the sclera with a spatula during gas injection to ensure convexity of the graft and host cornea. (E) Full gas fill with DMEK graft unfurled and centered. (F) Final gas fill at the conclusion of the case

did not feel it necessary to explant it prior to proceeding with endothelial keratoplasty.

A critical step in DMEK surgery is final fixation of the graft under a gas bubble, which poses a risk of IOL dislocation into the vitreous chamber, especially in previously vitrectomized eyes [7]. Due to iris fixation of the IOL, the pupil diameter could be larger than ideal. Rock, et al. describe one case of successful DMEK in a patient with previous IF-IOL. However, it is important to note that an Artisan lens was used in their case, which is not available for aphakia in the United States. The Artisan IOL is fixated to the iris with claws which are enclavated onto the iris, not sutured [16]. The monofilament haptics of our patient's 3-piece IOL were sutured to the iris at two locations, allowing for tilt of the IOL with tapping to manipulate the DMEK graft. This allows for the possibility of loss of the DMEK tissue into the posterior segment. This risk can be slightly mitigated by utilizing a lens with a large optic, such as the $6.0 \mathrm{~mm}$ optic used in our patient. IOLs sutured to the iris also allow for movement of air or gas into the posterior segment, which can make placement of an adequate anterior chamber gas bubble more difficult. Use of external posterior segment pressure can temporarily shallow the anterior chamber to aid with unfurling of the graft.

Of note, our patient's preoperative astigmatism was +1.25 diopters, which decreased to +0.75 diopters at the three-month postoperative visit. Though generally endorsed as a refractively near-neutral surgery, DMEK may potentially reshape the corneal surface, especially in eyes that have undergone anterior corneal manipulation $[6,17]$.

Here we have reported successful DMEK surgery in a patient with prior RK and an iris-sutured IOL (in addition to Fuchs dystrophy and prior anterior vitrectomy). There were no intraoperative complications, and uncorrected VA improved from 20/80 preoperatively to $20 / 20$ postoperatively. Accordingly, while technically challenging, DMEK in eyes with RK and IF-IOL is possible and can offer effective visual rehabilitation.

\section{Abbreviations}

AC: Anterior chamber; BCVA: Best corrected visual acuity; DMEK: Descemet membrane endothelial keratoplasty; DORC: Dutch Ophthalmic Research Center; ERM: Epiretinal membrane; IF-IOL: Iris-fixated intraocular lens; IOL: Intraocular 
lens; OCT: Optical coherence tomography; OD: Right eye; OS: Left eye; OU: Both eyes; RK: Radial keratotomy; SF6: Sulfur hexafluoride; VA: Visual acuity

\section{Supplementary Information}

The online version contains supplementary material available at https://doi. org/10.1186/s12886-021-02103-1.

Additional file 1 .

\section{Acknowledgements}

Not applicable.

\section{Authors' contributions}

AA - Reviewed and analyzed clinical information of the patient, reviewed literature, and drafted the manuscript. TS - Reviewed and edited the manuscript. MS - Reviewed and edited the manuscript. NN - Reviewed literature and reviewed and edited the manuscript. All authors read and approved the final manuscript.

\section{Funding}

Funding was not required for this study.

\section{Availability of data and materials}

Data sharing is not applicable to this article as no datasets were generated or analyzed during the current study.

\section{Declarations}

\section{Ethics approval and consent to participate}

Written informed consent was obtained from the patient for publication of this case report and any accompanying images.

\section{Consent for publication}

Written informed consent was obtained from the patient for publication of this case report and any accompanying images.

\section{Competing interests}

The authors declare that they have no competing interests.

Received: 7 December 2020 Accepted: 8 September 2021 Published online: 20 September 2021

\section{References}

1. Guerra FP, Anshu A, Price MO, Giebel AW, Price FW. Descemet's membrane endothelial keratoplasty: prospective study of 1-year visual outcomes, graft survival, and endothelial cell loss. Ophthalmology. 2011. doi: https://doi. org/10.1016/j.ophtha.2011.06.002.

2. Grimmett MR, Holland EJ. Complications of small clear-zone radial keratotomy. Ophthalmology. 1996;103(9):1348-56.

3. Jory WJ. Radial keratotomy: 500 consecutive cases. Eye. 1989;3:663-71.

4. Moshirfar M, Ollerton A, Rodmerh TS, Hsu M. Radial keratotomy associated endothelial degeneration. Clin Ophthalmol. 2012;6:213-8.

5. Akella SS, Chuck RS, Lee JK. Descemet membrane endothelial keratoplasty for endothelial decompensation after previous radial keratotomy. Am J Ophthalmol Case Rep. 2019. doi: https://doi.org/10.1016/j.ajoc.2019.100503.

6. Parker JS, Parker JS, Melles GR. Clinical outcomes of Descemet membrane endothelial keratoplasty in eyes with previous radial keratotomy. Cornea. 2018. doi: https://doi.org/10.1097/ICO.0000000000001719.

7. Rock D, Rock T, Bartz-Schmidt K, Yoeruek E. Descemet membrane endothelial keratoplasty in cases with existing scleral-sutured and irissutured intraocular lenses. BMC Ophthalmol. 2014. doi: https://doi.org/10.11 86/1471-2415-14-6.

8. Cursiefen C, Kuchle M, Naumann GO. Changing indications of penetrating keratoplasty: histopathology of 1,250 corneal buttons. Cornea. 1998;17:468-70.

9. Holz HA, Meyer JJ, Espandar L, Tabin GC, Mifflin MD, Moshirfar M. Corneal profile analysis after Descemet stripping endothelial keratoplasty and its relationship to postoperative hyperopic shift. J Cataract Refract Surg. 2008; 34(2):211-4
10. Goldich Y, Artornsombidth P, Avni-Zauberman N, Perez M, Ulate R, Elbaz U, Rootman DS. Fellow eye comparison of corneal thickness and curvature in descemet membrane endothelial keratoplasty and descemet stripping automated endothelial keratoplasty. Cornea. 2014;33(6):547-50.

11. Romano V, Pagano L, Gadhvi KA, Coco G, Titley M, Fenech MT, et al. Clinical outcomes of pre-loaded ultra-thin DSAEK and pre-loaded DMEK. BMJ Open Ophthalmol. 2020;5(1):e000546.

12. Woo JH, Arundhati A, Chee S, Tong W, Li L, Htoon HM, et al. Endothelial keratoplasty with anterior chamber intraocular lens versus secondary posterior chamber intraocular lens. Br J Ophthalmol. 2020. doi: https://doi. org/10.1136/bjophthalmol-2020-316711.

13. Masket S, Fram NR, Cho A, Park I, Pham D. Surgical management of negative dysphotopsia. J Cataract Refract Surg. 2018;44(1):6-16.

14. Droutsas K, Lazaridis A, Kymionis G, Chatzistefanou K, Papaconstantinou D, Sekundo W, Koutsandrea C. Endothelial keratoplasty in eyes with a retained angle-supported intraocular lens. Int Ophthalmol. 2019;39(5):1027-35.

15. Liarakos VS, Ham L, Dapena I, Tong CM, Quilendrino R, Yeh R, Melles GRJ. Endothelial keratoplasty for bullous keratopathy in eyes with an anterior chamber intraocular lens. J Cataract Refract Surg. 2013;39(12):1835-45.

16. Negretti GS, Chan WO, Muqit MMK. Artisan iris-claw intraocular lens implantation in vitrectomised eyes. Eye. 2020; https://doi-org.proxy.lib. umich.edu/10.1038/s41433-020-1022-x

17. Gupta R, Kinderyte R, Jacobs DS, et al. Elimination of anterior corneal steepening with Descemet membrane endothelial keratoplasty in a patient with Fuchs dystrophy and keratoconus: implications for IOL calculation. Cornea. 2017;36:1260-2.

\section{Publisher's Note}

Springer Nature remains neutral with regard to jurisdictional claims in published maps and institutional affiliations.

Ready to submit your research? Choose BMC and benefit from:

- fast, convenient online submission

- thorough peer review by experienced researchers in your field

- rapid publication on acceptance

- support for research data, including large and complex data types

- gold Open Access which fosters wider collaboration and increased citations

- maximum visibility for your research: over $100 \mathrm{M}$ website views per year

At BMC, research is always in progress.

Learn more biomedcentral.com/submissions 